\title{
Heparin-coated vs. Non-coated Cardiopulmonary Bypass Circuits: Comparing Immediate Results with Different Target Activated Clotting Time
}

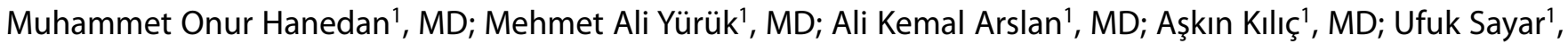
MD; illker Mataracı ${ }^{1}, \mathrm{MD}$

\begin{abstract}
Objective: To compare immediate postoperative results in patients receiving heparin-albumin-coated and non-coated circuits.

Methods: A total of 241 patients undergoing on-pump cardiac surgery were divided into two groups: those receiving heparin-coated circuits (Bioline ${ }^{\circledR}$, Maquet Cardiopulmonary AG., Hirrlingen, Germany) and those receiving non-coated circuits (Maquet Cardiopulmonary AG., Hirrlingen, Germany).

Results: Activated clotting times (ACT) during cardiopulmonary bypass (CPB) were significantly shorter in the heparin-albumincoated group than in the non-coated group (355.64 \pm 34.12 vs.
\end{abstract}

560.38 \pm 90.20 , respectively, $P=0.001$ ). In-hospital mortality and postoperative stroke rates and lengths of intensive care unit stay were similar between the groups; in contrast, in the heparinalbumin-coated group, patients had significantly better outcomes for hospital stay, drainage, and need for erythrocyte transfusion.

Conclusion: Heparin-coated circuits and reduced level of systemic heparinization with 300 seconds of target ACT level in cardiac surgery under CPB are safe and result in a very satisfactory clinical course.

Keywords: Cardiopulmonary Bypass. Heparin. Hospital Mortality. Length of Stay. Erythrocyte Transfusion. Silver. Cardiac Surgical Procedures. Intensive Care Units. Postoperative Period.

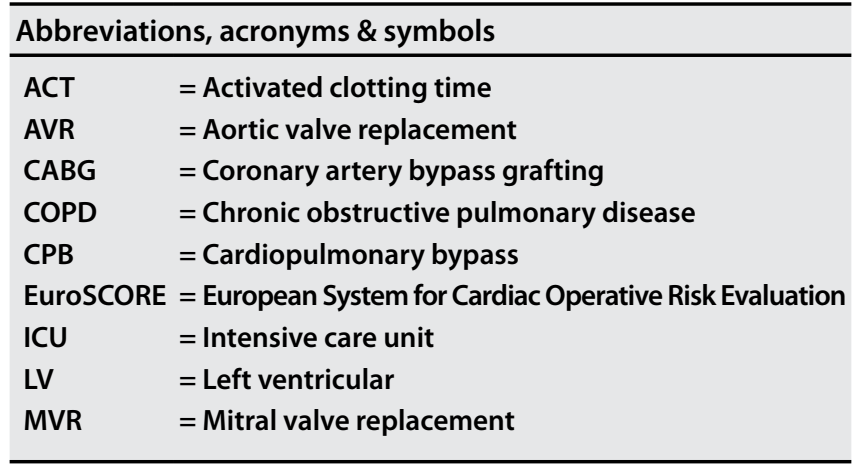

\section{INTRODUCTION}

Activation of the complement cascade, oxidative stress, and coagulation pathways induced by cardiopulmonary bypass (CPB) resulting in systemic inflammatory response syndrome after open heart surgery may cause several complications, like

'Department of Cardiovascular Surgery, University of Health Sciences, Ahi Evren Thoracic and Cardiovascular Surgery Training and Research Hospital, Trabzon, Turkey.

This study was carried out at the Department of Cardiovascular Surgery, University of Health Sciences, Ahi Evren Thoracic and Cardiovascular Surgery Training and Research Hospital, Trabzon, Turkey. bleeding or organ dysfunctions ${ }^{[1]}$. Several CPB circuits with heparin-coated or surface-modifying agents are available. These systems have been shown to reduce inflammatory response and to provide better hemocompatibility.

To avoid circuitry blood clotting and thromboembolic complications, systemic heparin is administered to both the patient and the circuits ${ }^{[2]}$. Heparin is the most known anticoagulant used in CPB because of its rapid onset, effectiveness, ease of reversal by protamine, and low cost. While heparin is most known for its impact on the coagulation pathway, there is some evidence that heparin also affects fibrinolysis and platelet function independent of CPB. The effect on fibrinolysis and platelets may result in postoperative bleeding or increasing the transfusions ${ }^{[3]}$.

Heparin dosage for anticoagulation during CPB is calculated with an empiric formula based on the patient's body weight and preoperative activated clotting time (ACT). Commonly for initiating $C P B, A C T$ length must be $>480$ seconds with non-

Correspondence Address:

Muhammet Onur Hanedan

(iD) https://orcid.org/0000-0002-8363-7861

Department of Cardiovascular Surgery, University of Health Sciences, Ahi Evren

Thoracic and Cardiovascular Surgery Training and Research Hospital

Ahi Evren GKD EAH Soğuksu Mahellesi, Vatan Caddesi, no 9, Trabzon, Türkiye

Zip Code: 61040

E mail: ohanedan@hotmail.com

Article received on October $11^{\text {th }}, 2019$

Article accepted on February $11^{\text {th }}, 2020$. 
heparin-coated circuits. Some authors have reported that this full-dose anticoagulation approach unnecessarily exposes the patient to excessive blood loss ${ }^{[4]}$. Heparin coating may decrease the appropriate ACT levels, which are resulting in less transfusion and bleeding.

In this study, we aimed to compare immediate postoperative results (e.g., drainage, erythrocyte transfusion, postoperative stroke, and mortality) in patients receiving heparin-albumincoated and non-coated circuits.

\section{METHODS}

We performed a retrospective database review between January $1^{\text {st }}, 2015$ and December $31^{\text {st }}, 2016$ and identified a total of 241 adult patients who underwent on-pump cardiac surgery. Emergency surgeries, minimal invasive procedures, and nonsternotomy patients were not included in the study. Patients were divided into two groups according to circuit coating property.

In our clinic, we were using non-coated circuits (Maquet Cardiopulmonary AG., Hirrlingen, Germany) before 2016 routinely, and by 2016 we started to use heparin-albumin-coated circuits (Bioline ${ }^{\circledast}$, Maquet Cardiopulmonary AG., Hirrlingen, Germany). All perfusion tubing systems were completely coated, except for the cannulas.

Hemochron ${ }^{\oplus} \mathrm{J}$. Signature plus Whole Blood Microcoagulation System (Accriva Diagnostics, San Diego, California, United States of America) was used to measure ACT. This system uses silica, kaolin, and phospholipid as activators and measures the elapsed time between the start of the test and clot formation, and the ACT is automatically converted to a reference celite-based ACT value.

Before CPB, $300 \mathrm{IU} / \mathrm{kg}$ of heparin (Vasparin ${ }^{\circledR}$ Tekirdag, Turkey) was administered intravenously to patients receiving non-coated circuits. Readministration of $5000 \mathrm{IU}$ heparin boluses took place if the ACT was $<480$ seconds. A reduced dose of heparin (150 $\mathrm{IU} / \mathrm{kg}$ ) was administered for systemic anticoagulation to patients receiving heparin-albumin-coated circuits. Readministration of 2500 IU heparin boluses took place if the ACT was $<300$ seconds. ACT was repeatedly determined during $C P B$, after protamine administration, and two hours postoperatively. Myocardial protection consisted of intermittent antegrade administration of cold blood cardioplegic solution. After completion of CPB, heparin was antagonized with protamine in a ratio of 1:1.

The amount of postoperative bleeding from the time of sternal closure until the drains were removed was recorded. Postoperative 24-hour drainage was used for analysis. Normovolemic anemia was accepted to a hematocrit level of 0.25 postoperatively; a level less than this was considered an indication for allogeneic red blood cell transfusion.

CPB was performed with a Terumo ${ }^{\oplus}$ Advanced Perfusion System 1 (Terumo Cardiovascular Group, Ann Arbor MI) with a non-pulsatile flow control and at a flow rate of $2.4 \mathrm{~L} / \mathrm{m}^{2} / \mathrm{min}$. Systemic moderate hypothermia $\left(30^{\circ} \mathrm{C}\right)$ was used in coronary and valve surgery; in aortic procedures, deep hypothermia (24 ${ }^{\circ} \mathrm{C}$ ) was used. Standard adult sizes of the circuits were used and primed with $1000 \mathrm{~mL}$ of lactated ringer.
Antiplatelet therapy was not stopped before surgery. Vitamin Kantagonist was stopped and changed to low-molecular-weight heparin before surgery.

\section{Statistical Analysis}

Data were expressed as mean \pm standard deviation for quantitative variables and as number and percentage for categorical variables. The groups were compared by Student's $t$-test for continuous variables and the $c^{2}$ or Fisher's exact test for categorical variables. A $P$-value $<0.05$ was statistically significant.

\section{RESULTS}

The patients' baseline demographic characteristics are summarized in Table 1 and they were comparable, except for a higher incidence of extracardiac arteriopathy in the heparinalbumin-coated group. Performed operations are mentioned in Table 2. The chief procedure was coronary artery bypass grafting (CABG), for $60 \%$ of the patients in the heparin-albumincoated group and $83 \%$ in the non-coated group. Table 3 shows the operative and postoperative variables. In heparinalbumin-coated group, we observed significantly longer crossclamp times. ACT during CPB is significantly shorter in the heparin-albumin-coated group than in the non-coated group (355.64 \pm 34.12 vs. $560.38 \pm 90.20$, respectively, $P=0.001$ ) In-hospital mortality rates, postoperative cerebrovascular event rates, and lengths of intensive care unit (ICU) stay were similar between the groups; in contrast, patients in the heparin-albumin-coated group had significantly better outcomes for hospital stay, drainage, and need for erythrocyte transfusion.

\section{DISCUSSION}

This study revealed similar clinical outcomes of non-coated and albumin-heparin-coated circuits in terms of in-hospital mortality rates, postoperative cerebrovascular event rates, and lengths of ICU stay. Furthermore, better outcomes for hospital stay, amount of mediastinal drainage, and need for erythrocyte transfusion were achieved with coated circuits. In fact, it is obvious that the proposal of maintaining CPB using heparin in a lesser amount with a shorter ACT and, at the same time, using bioartificial surfaces will have positive results. In this study, the rational basis of this hypothesis was investigated with literature examples.

Conventionally, an empirical dose of heparin has been used to inhibit coagulation for initiating and maintaining CPB to achieve an ACT level > 480 seconds. Achieving this target ACT level by giving high doses of heparin is associated with significantly higher postoperative blood $\operatorname{loss}^{[5]}$. A heparin titration method used in a study to achieve conventional ACT level resulted in using low doses of heparin, which is associated with lower blood loss ${ }^{[6]}$. In this recent study, we used low-dose heparin with titration model with a significantly lower ACT level.

Heparin-coated surfaces do not only reduce the systemic heparinization, they also reduce the systemic inflammatory process and oxidative stress ${ }^{[7]}$. Although the endpoint of our study is not to assay inflammatory responses, using more 
Table 1. Patients' preoperative demographic and clinical characteristics.

\begin{tabular}{|c|c|c|c|}
\hline & Group 1 & Group 2 & \\
\hline & $\begin{array}{l}\text { Heparin-albumin-coated circuits } \\
\qquad(n=135)\end{array}$ & $\begin{array}{l}\text { Non-coated circuits } \\
\qquad(n=106)\end{array}$ & $P$-value \\
\hline Age (years) & $63.87 \pm 10.16$ & $62.17 \pm 10.61$ & 0.196 \\
\hline Logistic EuroSCORE ॥ & $4.52 \pm 4.44$ & $4.51 \pm 4.97$ & 0.987 \\
\hline Male patients & $100(74.1 \%)$ & $79(74.5 \%)$ & 0.996 \\
\hline Body surface area $\left(\mathrm{m}^{2}\right)$ & $1.84 \pm 0.18$ & $1.86 \pm 0.18$ & 0.476 \\
\hline LV ejection fraction (\%) & $53.83 \pm 9.94$ & $54.27 \pm 10.07$ & 0.732 \\
\hline Smoking history & $60(44.4 \%)$ & $48(45.3 \%)$ & 0.897 \\
\hline Diabetes mellitus & $73(54.1 \%)$ & $57(53.8 \%)$ & 0.963 \\
\hline Hypertension & $94(69.6 \%)$ & $67(63.2 \%)$ & 0.293 \\
\hline Creatinine & $1.04 \pm 0.31$ & $1.16 \pm 0.74$ & 0.086 \\
\hline COPD & $37(27.4 \%)$ & $29(27.4 \%)$ & 0.993 \\
\hline Extracardiac arteriopathy & $29(21.5 \%)$ & $12(11.3 \%)$ & 0.037 \\
\hline Cerebrovascular disease & $2(1.5 \%)$ & $2(1.9 \%)$ & 10.999 \\
\hline Atrial fibrillation & $23(17 \%)$ & $16(15.1 \%)$ & 0.684 \\
\hline Hematocrit (\%) & $40.89 \pm 4.98$ & $41.17 \pm 4.44$ & 0.642 \\
\hline
\end{tabular}

$\mathrm{COPD}=$ chronic obstructive pulmonary disease; EuroSCORE=European System for Cardiac Operative Risk Evaluation; LV=left ventricular Data are expressed as mean \pm standard deviation or as number and percentage. $P<0.05$ was considered statistically significant.

Table 2. Type of operation in groups.

\begin{tabular}{|c|c|c|}
\hline & Group 1 & Group 2 \\
\hline & $\begin{array}{l}\text { Heparin-albumin-coated circuits } \\
\qquad(n=135)\end{array}$ & $\begin{array}{l}\text { Non-coated circuits } \\
\quad(n=106)\end{array}$ \\
\hline CABG & 81 & 88 \\
\hline MVR/Mitral repair & 11 & 4 \\
\hline AVR & 14 & 4 \\
\hline$A V R+C A B G$ & 8 & 1 \\
\hline AVR+MVR & 3 & 1 \\
\hline Aortic procedures ( \pm AVR) & 8 & 5 \\
\hline
\end{tabular}

$\mathrm{AVR}=$ aortic valve replacement; $\mathrm{CABG}=$ coronary artery bypass grafting; $\mathrm{MVR}=$ mitral valve replacement

biocompatible surfaces is related with better outcomes. Tayama E. et al. ${ }^{[8]}$ showed reduced inflammatory response with heparincoated circuits, but no benefits in clinical outcomes. In that study, heparin administration and target ACT levels were the same in both heparin-coated and non-coated groups. Similarly, there were no significant clinical outcomes in the study by Reser
D. et al. ${ }^{[1]}$, in which three different biocompatible surface circuits were compared and heparin administration and target ACT levels were conventionally set. These consequences support our hypothesis.

Another important debate is that if low target ACT levels are safe or not. Ovrum E. et al. ${ }^{[4]}$ showed that a median ACT level 
Table 3. Comparison of operative and postoperative results.

\begin{tabular}{|c|c|c|c|}
\hline & Group 1 & Group 2 & \\
\hline & $\begin{array}{l}\text { Heparin-albumin-coated circuits } \\
\qquad(n=135)\end{array}$ & $\begin{array}{l}\text { Non-coated circuits } \\
\qquad(n=106)\end{array}$ & $P$-value \\
\hline Operation time (min) & $219.67 \pm 53.34$ & $222.97 \pm 47.20$ & 0.616 \\
\hline Cross-clamp time (min) & $58.29 \pm 22.49$ & $51.67 \pm 23.56$ & 0.027 \\
\hline CPB time (min) & $90.78 \pm 29.75$ & $84.25 \pm 29.45$ & 0.091 \\
\hline ACT (sec) (during CPB) & $355.64 \pm 34.12$ & $560.38 \pm 90.20$ & 0.001 \\
\hline ACT (sec) (after 2 hours) & $103.58 \pm 2.71$ & $104.24 \pm 3.69$ & 0.125 \\
\hline $\begin{array}{l}\text { Duration of mechanical ventilation } \\
\text { (hours) }\end{array}$ & $13.9 \pm 45.2$ & $11.65 \pm 19.22$ & 0.633 \\
\hline Intensive care unit stay (hours) & $66.70 \pm 65.01$ & $75.07 \pm 56.38$ & 0.294 \\
\hline Drainage $(\mathrm{mL})$ & $529.11 \pm 267.97$ & $660.75 \pm 279.73$ & 0.001 \\
\hline Re-exploration for bleeding & $3(2.2 \%)$ & $7(6.6 \%)$ & 0.111 \\
\hline Erythrocyte transfusion (U) & $1.27 \pm 1.32$ & $2.08 \pm 2.28$ & 0.001 \\
\hline Postoperative stroke & $3(2.2 \%)$ & $2(1.9 \%)$ & 0.998 \\
\hline 30-day hospital death & $3(2.2 \%)$ & $2(1.9 \%)$ & 0.998 \\
\hline Hospital stay (days) & $4.48 \pm 3.25$ & $9.97 \pm 6.88$ & 0.027 \\
\hline
\end{tabular}

$\mathrm{ACT}=$ activated clotting time; $\mathrm{CPB}=$ cardiopulmonary bypass

Data are expressed as mean \pm standard deviation or as number and percentage. $P<0.05$ was considered statistically significant.

(almost 300 seconds during (PB) was safe and resulted in a very satisfactory clinical course in 5,954 patients undergoing onpump CABG with heparin-coated circuits ${ }^{[4]}$. In this recent study, mean ACT level in heparin-coated circuits was 355 seconds during the CPB and it was not associated with adverse clinical outcome.

Heparin coating the circuits increases cost and this technology is not routinely used for short-time devices due to higher initial costs ${ }^{[9]}$. Therefore, the advantages of this system, like reduction in blood loss and reduction of ventilator dependence and length of hospital stay, make heparin-coated circuits more reasonable to use in terms of overall costs ${ }^{[10]}$.

Limited use of anticoagulation during CPB and risk for stroke is another concern which was investigated previously, and stroke and mortality rates were comparable in heparin-coated circuits vs. conventional ones ${ }^{[11]}$. In our assay, we found no significant difference between the groups for 30-day hospital mortality and postoperative stroke rates, similarly to the literature.

A meta-analysis demonstrates parallel results, that biocompatible circuits have a limited effect (lower transfusion needs and atrial fibrillation rate) on morbidity, leading to shorter ICU and hospital stays ${ }^{[12]}$. A review by Mahmood S. et al. ${ }^{[10]}$ about heparin-bonded CPB circuit showed that perfusion with heparin-coated and heparin-polymer-coated bypass does not increase the risk of adverse effects but reduces blood loss, re- operation rates, ventilation time, length of ICU and hospital stays, and is also associated with improved biocompatibility.

\section{Limitations}

The limitations of this study are its single-center nature, small sample size, and nonrandomized design. This study focused on immediate outcomes, so long-term follow-up data from randomized clinical trials will be needed to evaluate clinical outcomes.

\section{CONCLUSION}

Comparable postoperative stroke and mortality rates were found in contrast with less blood transfusion, lower drainage, short periods of postoperative ventilator support, and reduced hospital stay seen in the study group. In conclusion, heparincoated circuits and reduced level of systemic heparinization with a 300 seconds target ACT level in cardiac surgery under CPB are safe and result in a very satisfactory clinical course.

\section{No financial support.}

No conflict of interest. 


\section{Authors' roles \& responsibilities}

$\mathrm{MOH}$ Substantial contributions to the conception or design of the work; or the acquisition, analysis, or interpretation of data for the work; drafting the work or revising it critically for important intellectual content; agreement to be accountable for all aspects of the work in ensuring that questions related to the accuracy or integrity of any part of the work are appropriately investigated and resolved; final approval of the version to be published

MAY Substantial contributions to the conception or design of the work; or the acquisition, analysis, or interpretation of data for the work; drafting the work or revising it critically for important intellectual content; agreement to be accountable for all aspects of the work in ensuring that questions related to the accuracy or integrity of any part of the work are appropriately investigated and resolved; final approval of the version to be published

AKA Agreement to be accountable for all aspects of the work in ensuring that questions related to the accuracy or integrity of any part of the work are appropriately investigated and resolved; final approval of the version to be published

AK

Substantial contributions to the conception or design of the work; or the acquisition, analysis, or interpretation of data for the work; agreement to be accountable for all aspects of the work in ensuring that questions related to the accuracy or integrity of any part of the work are appropriately investigated and resolved; final approval of the version to be published

Drafting the work or revising it critically for important intellectual content; final approval of the version to be published

Drafting the work or revising it critically for important intellectual content; agreement to be accountable for all aspects of the work in ensuring that questions related to the accuracy or integrity of any part of the work are appropriately investigated and resolved; final approval of the version to be published

\section{REFERENCES}

1. Reser D, Seifert B, Klein M, DreizlerT, Hasenclever P, FalkV, et al. Retrospective analysis of outcome data with regards to the use of Phisio ${ }^{{ }_{-}}$, Bioline ${ }^{{ }_{-}}$ or Softline ${ }^{\circledR}$-coated cardiopulmonary bypass circuits in cardiac surgery. Perfusion. 2012:27(6):530-4. doi:10.1177/0267659112454558.

2. Teligui L, Dalmayrac E, Mabilleau G, Macchi L, Godon A, Corbeau JJ, et al. An ex vivo evaluation of blood coagulation and thromboresistance of two extracorporeal circuit coatings with reduced and full heparin dose. Interact Cardiovasc Thorac Surg. 2014;18(6):763-9. doi:10.1093/icvts/ivu011.

3. Lander H, Zammert M, FitzGerald D. Anticoagulation management during cross-clamping and bypass. Best Pract Res Clin Anaesthesiol. 2016;30(3):35970. doi:10.1016/j.bpa.2016.07.002.

4. Øvrum E, Tangen G, Tølløfsrud S, Skeie B, Ringdal MA, Istad R, et al. Heparinized cardiopulmonary bypass circuits and low systemic anticoagulation: an analysis of nearly 6000 patients undergoing coronary artery bypass grafting. JThorac Cardiovasc Surg. 2011;141(5):1145-9. doi:10.1016/j.jtcvs.2010.07.003.

5. Despotis GJ, Joist JH, Hogue CW Jr, Alsoufiev A, Kater K, Goodnough LT, et al. The impact of heparin concentration and activated clotting time monitoring on blood conservation. A prospective, randomized evaluation in patients undergoing cardiac operation. JThorac Cardiovasc Surg. 1995;1 10(1):46-54. doi:10.1016/S0022-5223(05)80008-X

6. Shuhaibar MN, Hargrove M, Millat MH, O'Donnell A, Aherne T. How much heparin do we really need to go on pump? A rethink of current practices. Eur J Cardiothorac Surg. 2004;26(5):947-50. doi:10.1016/j.ejcts.2004.07.009.

7. Sohn N, Marcoux J, Mycyk T, Krahn J, Meng Q. The impact of different biocompatible coated cardiopulmonary bypass circuits on inflammatory response and oxidative stress. Perfusion. 2009;24(4):231-7. doi:10.1177/0267659109351218.

8. Tayama E, Hayashida N, Akasu K, Kosuga T, Fukunaga S, Akashi H, et al. Biocompatibility of heparin-coated extracorporeal bypass circuits: new heparin bonded bioline system. Artif Organs. 2000;24(8):618-23. doi:10.1046/ j.1525-1594.2000.06615.x.

9. Voegele-Kadletz M, Wolner E. Bio artificial surfaces - blood surface interaction Mater Sci Eng. 2011;31(6):1195-1200. doi:10.1016/j.msec.2011.02.010

10. Mahmood S, Bilal H, Zaman M, Tang A. Is a fully heparin-bonded cardiopulmonary bypass circuit superior to a standard cardiopulmonary bypass circuit? Interact Cardiovasc Thorac Surg. 2012;14(4):406-14. doi:10.1093/icvts/ivr124.

11. Mangoush O, Purkayastha S, Haj-Yahia S, Kinross J, Hayward M, Bartolozzi F, et al. Heparin-bonded circuits versus nonheparin-bonded circuits: an evaluation of their effect on clinical outcomes. Eur J Cardiothorac Surg. 2007;31(6):1058-69. doi:10.1016/j.ejcts.2007.01.029.

12. Ranucci M, Balduini A, Ditta A, Boncilli A, Brozzi S. A systematic review of biocompatible cardiopulmonary bypass circuits and clinical outcome. Ann Thorac Surg. 2009;87(4):1311-9. doi:10.1016/j.athoracsur.2008.09.076. 